\title{
MOLT, AGE, AND IDENTIFICATION OF THE MASKED AND NAZCA BOOBIES IN CALIFORNIA
}

PETER PYLE, The Institute for Bird Populations, P.O. Box 518, Petaluma, California 94953; ppyle@birdpop.org

\begin{abstract}
I examined photographs compiled by the California Bird Records Committee to assess bill-color and plumage-color changes with molt of the primaries in Masked (Sula dactylatra) and Nazca (S. granti) boobies recorded in California. I evaluated a total of 134 individuals initially discovered between 5 April 1990 and 19 November 2019. For each individual I scored the stage of molt of the primaries, coloration of seven areas of the plumage, and color and brightness of both the base and tip of the bill. Two distinct bill-color patterns emerged as the birds aged from juvenile to definitive plumage. Birds with dusky, horn color (medium-pale brownish, often tinged mustard or olive), orange, and/or pink in the bill base commonly had brighter orange-yellow or golden yellow but not green in the bill tip. By contrast, birds with dark blue, green, and/or yellow in the bill base commonly had green and/or yellow but not orange in the bill tip, and the tip was less often brighter than the base. I propose that the first category represents Nazca Boobies and the second represents Masked Boobies. A horn-colored base and a brighter golden-yellow tip of the bill of birds in their first and second plumage cycles (including most juveniles) evidently indicates the Nazca Booby. Some birds probably reach definitive appearance by completion of their first primary molt, at 20-22 months of age. The central rectrices of apparent Nazca Boobies (by bill color) average whiter than those of apparent Masked Boobies, the extent of white increasing from juvenile to second basic to definitive plumage. But there is species overlap in this feature. According to provisional identifications in my sample, Nazca Boobies have outnumbered Masked Boobies in California (92 vs. 27 individuals through 2019).
\end{abstract}

The Nazca Booby (Sula granti) was split from the Masked Booby ( $S$. dactylatra) by the American Ornithologists' Union ([AOU] 2000) after Pitman and Jehl (1998) documented differences in morphology, bill color, and plumage color, along with assortative pairing and habitat selection on islands where both taxa breed. The Nazca Booby breeds primarily on the Galapagos Islands but also on Malpelo Island off Colombia and sparingly north to Clipperton Atoll and the Revillagigedo Islands off Mexico (Howell and Pyle 1997, Pitman and Jehl 1998, AOU 2000). The Masked Booby of subspecies S. d. personata (including S. d. californica; Pitman and Jehl 1998) breeds on islands throughout the tropical Pacific Ocean. In the eastern Pacific, it breeds primarily on Clipperton Atoll and the Revillagigedo Islands and sparingly on the Alijos Rocks off Baja California (Everett and Pitman 1995). Hybridization, or at least mixed pairing, of Masked and Nazca boobies has been reported occasionally on Clipperton Atoll and the Revillagigedo Islands (Pitman and Jehl 1998, California Bird Records Committee [CBRC] 2007) as well as in the Hawaiian Islands (VanderWerf et al. 2008).

Boobies apparently lack a preformative molt; the molt that replaces the juvenile plumage following the first cycle is the second prebasic. This molt (and the second plumage cycle) begins when the bird is 7-9 months old, with the dropping of the tertials and the innermost primary, p1 (Pyle 2008, Howell 2010). The primaries are molted sequentially and distally, the outermost pri- 
mary (p10) being replaced when the bird is an estimated 18-22 months old, before which time a second wave of primary molt from $\mathrm{p} 1$ commences the third plumage cycle in a Staffelmauser or stepwise molt sequence (Dorward 1962, Pyle 2006, 2008, Howell 2010). The remaining secondaries and rectrices are replaced during molt of primaries, the rectrices beginning with the central pair and proceeding laterally but in a haphazard and often asymmetrical sequence. In adults, the prebasic molt occurs annually and is complete or nearly so, with up to three waves of active molt proceeding through the primaries at the same time (Pyle 2008). Molt takes place largely at sea, when birds are not breeding, and it is likely continuous or nearly so throughout the nonbreeding period (Pyle 2008, Howell 2010).

During the second prebasic and subsequent molt cycles, the head, back, rump, and upper secondary coverts gradually change from entirely or predominantly brown in juveniles to entirely white in adults. The definitive plumage is reportedly attained during the third or fourth cycle. But there appears to be substantial individual variation in the rate of plumage maturation, which is poorly known because of lack of data from individuals of known age (Pyle 2008).

In the third to definitive basic plumages, the bill of a Nazca Booby is pinkish orange to orange at the base, while that of a Masked Booby is greenish yellow to yellow, allowing virtually all birds to be distinguished in the field (Pitman and Jehl 1998, Roberson 1998, CBRC 2007, Howell et al. 2014, Howell and Zufelt 2019). The identification of juveniles and birds undergoing the second prebasic molt, however, has been problematic. The bill color is dark or dull in nestlings and juveniles of both species. It has been speculated that, in the Nazca Booby, the orangish coloration of adults' bills may begin appearing at $4-8$ months of age, and should allow identification of all birds at 12 months of age (Pyle 2008, R. Pitman in Singer et al. 2020). But this has not been based on evidence from birds of known age, and the rate of bill-color change varies with the individual. Precisely when and how the bill colors change in Masked and Nazca boobies in their first and second plumage cycles is currently undocumented.

Various plumage features have also been proposed to distinguish firstcycle birds, including a white hind collar that is more frequent and distinct in juvenile Masked Boobies than in juvenile Nazca Boobies, and more white at the base of the central pair of rectrices in the Nazca than in the Masked (Pitman and Jehl 1998, Roberson 1998, Pyle 2008, Howell et al. 2014, Howell and Zufelt 2019). However, juveniles of each species have been reported to show characters of the other species (Roberson 1998, Pyle 2008, Howell et al. 2014, Rottenborn et al. 2016). Because birds of these ages are rarely found on the breeding grounds after fledging, assessment of change in these characters relative to molt and bleaching of the plumage has been equivocal.

Both the Masked and Nazca boobies have been recorded as vagrants in California and Oregon (CBRC 2007, Rottenborn et al. 2016, McCaskie et al. 2018, OBRC 2020, Singer et al. 2020), and at least one adult Nazca Booby has strayed as far north as the Gulf of Alaska (Gibson et al. 2018). Through 2017, the CBRC had accepted records of 26 Masked Boobies and 15 Nazca Boobies from California, as well as of 25 Masked/Nazca Boobies that it did 
not distinguish to species (CBRC 2007, Singer et al. 2020). In 2018 and 2019 a surge of additional records representing 97 individuals was submitted, and by February 2020 the CBRC had accepted records of 43 Masked, 59 Nazca, and 43 Masked/Nazca boobies (T. Benson pers. comm.). The CBRC continues to use bill color as the only criterion distinguishing these two species, but its members have struggled with many records of first-cycle and second-cycle birds because of lack of specific knowledge regarding bill-color development in each species, along with variability in the appearance of bill colors in photographs taken at different angles of lighting, as taken by different cameras, and as viewed on different computer monitors (CBRC 2007, McCaskie et al. 2018, Singer et al. 2020).

Many birds that occurred in California in 2018 and 2019 were well photographed during the second prebasic molt of their primaries, allowing for a broad comparison of the bill color and plumage of individuals at various stages of molt and, hence, estimated age through the first and second plumage cycles. Here I assess the progress of molt, plumage change, bill-color change, and identification of all Masked or Nazca boobies photographed in California through 2019. My goals were (1) to assess bill-color and plumagecolor changes as molt of the primaries progresses from the first through the definitive molt cycles, (2) assess age-determination criteria, and (3) suggest criteria by which these two species can be identified in the first and second plumage cycles.

\section{METHODS}

I reviewed all photographs of Masked and Nazca boobies taken in California and submitted to the CBRC through 2019. These are listed in Appendix 1, available at www.westernfieldornithologists.org/archive/V51/Pyle-Boobies. I evaluated a total of 147 accepted records, one record that was not accepted because the bird rode on a ship from Mexican waters, and 10 pending records. The committee considered 11 of the accepted records to represent the same bird as in one or more other records. In these cases I assessed only the record with the most complete photographic documentation, except in one case (CBRC 2003-065 and 2003-128) in which I considered them different individuals (see Appendix 1). All records but five were of single birds. The exceptions involved two (three records), three, or four birds (see Appendix 1). In these cases I evaluated each individual separately. Accepted records that did not include photographs $(n=17)$ or included only very poor photographs, precluding any assessment of bill color or plumage patterns $(n=$ 5 ), were excluded from analysis, leaving a total of 134 individuals assessed. These birds were initially discovered on dates from 5 April 1990 (CBRC 1990-052) to 14 November 2019 (2019-179). With respect to season, the birds were initially discovered during all months of the year except March, though predominantly from July to October (Figure 1).

For each individual I attempted to score the stage of primary molt, the color of seven areas of the plumage (head, nape, lower back, upperwing coverts, uppertail coverts, underwing coverts, and central rectrices), and the color of the bill base and bill tip. I could assess primary molt on 108 of 
the 134 individuals, categorizing it as active $(n=83)$ or inactive $(n=25)$. If feasible, I scored the progression of replacement of the juvenile primaries during the second prebasic molt $(n=62)$ as the outermost primary that had been dropped or was growing, from p0 (primary 1 not dropped yet) to p10 (primary 10 growing).

I scored the head, nape, back, uppertail coverts, upperwing coverts, and underwing coverts from 0 to 5 , as each progressed from essentially all dark (0) to all white (5). Coloration of the central rectrices was also scored from 0 to 5 on the basis of the extent of white visible beyond the tips of the longest uppertail coverts, from none (0) to white or white with small dark markings (5). I categorized the generation of the central rectrices as juvenile, second basic, or definitive basic as based on replacement of the primaries and body plumage. Two individuals showed full-grown central rectrices of different generations, each of which I scored separately. Sample sizes for the seven plumage variables ranged from 131 for head color to 80 for underwing color; some individuals were not scored for one or more variables because the area was not visible or reliably assessable in available photographs.

I categorized the bill base (basal $~ 65 \%$ ) and bill tip (distal $~ 35 \%$ ) as up to two of seven colors, one dominant and one secondary. For example, a bill base of "greenish yellow" was predominantly yellow and secondarily (e.g., washed) green. In some cases only one color appeared evident, and in these I assigned it as both dominant and secondary. Colors included dusky (dark grayish to blackish), dark blue, horn (medium-pale brownish, often tinged mustard or olive), green, yellow, orange, and pink. The bill base could be any of these seven colors, whereas only three, green, yellow, and orange, were found in the bill tip. In addition, I scored the brightness of both base and tip colors as dull, medium-dull, medium, medium-bright, or bright. All colors were scored on a single laptop monitor, on which the warmth of colors was roughly average when compared against the same images of Masked and Nazca boobies on five or six other computer monitors during the CBRC's 2019 meeting in Los Angeles. To reduce unintended bias, I scored bills as much as possible without referring to the species under which the record was being considered or had been accepted by the CBRC. I scored most bills (74\% of 120 individuals) in one sitting, and changed no score in light of subsequent reference to species identification by the CBRC.

\section{RESULTS}

\section{Primary Molt}

Seven individuals were in juvenile plumage and had not started primary molt (primary score p0). In 56 individuals, replacement of juvenile primaries was in progress and the molt could be scored from p1 to p10 (Figure 2). Nine birds with juvenile outer primaries could not be assessed for progress of molt of the inner primaries. In no bird did the molt of juvenile primaries appear to have been suspended, while several (potentially all) boobies replacing the juvenile $\mathrm{p} 9$ and/or $\mathrm{p} 10$ had begun a second wave of primary molt at $\mathrm{p} 1$. From the distribution of data, I assigned each bird undergoing molt of juvenile primaries to one of six categories for analysis of bill color and plumage 


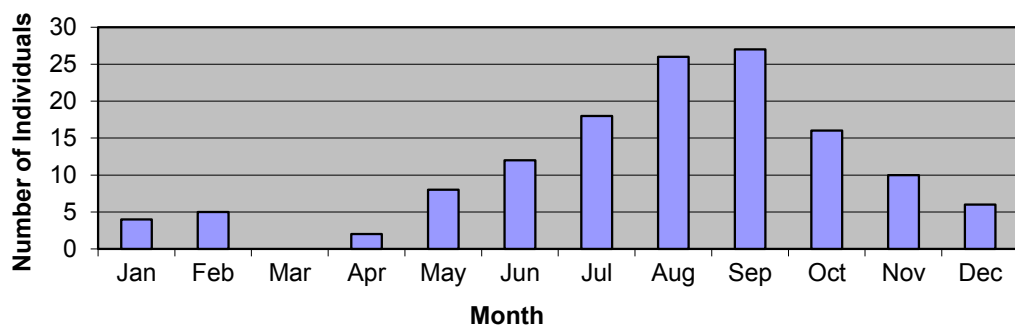

FIGURE 1. Seasonal distributions of Masked and Nazca boobies recorded in California, indicating a peak in observations from June to October. Dates are of the initial detection; some individuals remained into subsequent months including March and April.

change by age: $\mathrm{p} 0(n=6), \mathrm{p} 1-\mathrm{p} 4(n=13), \mathrm{p} 5-\mathrm{p} 6(n=8), \mathrm{p} 7(n=12), \mathrm{p} 8(n$ $=13)$, and $\mathrm{p} 9-\mathrm{p} 10(n=20)$. A seventh category included birds in their third cycle in which growth of p10 was completed during the second prebasic molt and a second wave of replacement had begun or presumably begun at $\mathrm{p} 1(n$ $=12$ ). Among these, four were in active molt in which the second wave of replacement had reached $\mathrm{p} 3(n=1), \mathrm{p} 4(n=1)$, or $\mathrm{p} 5(n=2)$. The molt had been suspended after the second wave reached $\mathrm{p} 3$ in one bird and $\mathrm{p} 4$ in two birds. For 5 of the 12 birds I could not determine if a molt was in progress. I considered individuals with completely white body feathers and wing coverts $(n=40)$ to be in definitive basic plumage; in 17 of these the primaries were in active molt, in 13 they were not in active molt, and in 10 birds I could not determine the molt status.

\section{Bill Color}

I was able to score bill color in 120 of the 134 individual boobies. In the remaining 14 birds the bill colors could not be reliably assessed because of post-mortem changes (carcasses or specimens) or unfavorable lighting, distance, or angle of the bird in photographs. For the bill base, I recorded the primary and/or secondary color as including dusky in 14 individuals, as dark blue in 22 , as horn in 34 , as green in 16, as yellow in 29 , as orange in 61 , and as pink in 19. I recorded the bill tip as including green in 18 individuals, yellow in all 120, and orange in 82 .

Combinations of colors of the bill base and bill tip fell into two distinct categories. Birds with dusky, horn, orange, and/or pink in the bill base commonly had yellow and orange in the bill tip, but none of these birds had green in the bill tip (Figure 3). By contrast, birds with dark blue, green, and/or yellow in the bill base commonly had green and/or yellow in the bill tip, but only three with these colors in the base were scored with orange, each with blue in the base and orange in the tip (see below). The predominant and secondary colors in the bill base were also associated nonrandomly. For example, no bill bases with dusky, horn, orange, or pink were scored with green as well, and only two of these were also scored with yellow (one as yellowish-horn and one as yellowish-orange). Likewise, no bill bases with dark blue, yellow, or green were also scored with orange or pink. 


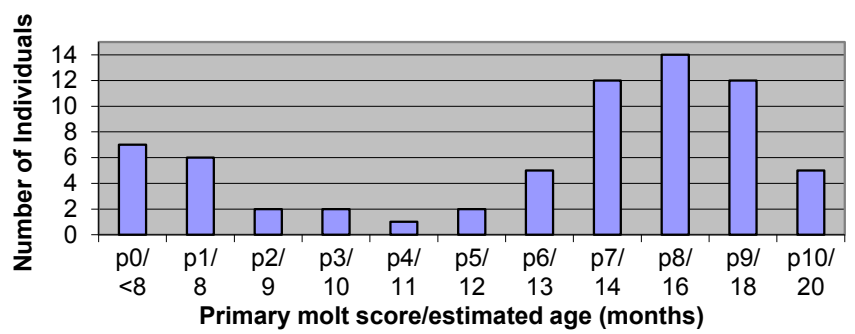

FIgURE 2. Number of subadult Masked and Nazca boobies recorded in California by stage of primary molt and estimated age. Ages are estimated from data on progression of molt in marked birds of an Atlantic population of the Masked Booby (Dorward 1962).

From these differences and further analysis of bill-color changes by age (below), I propose that the birds in the first category, with more dusky, horn, orange, and pink scored in the bill, be considered, provisionally, as Nazca Boobies and those in the second category, with more blue and green in the bill, be considered, provisionally, as Masked Boobies. The three individuals with both bluish in the base and orange in the tip, along with two individuals that showed conflicting colors in different photographs, were analyzed separately (see Discussion for more on these five birds). On the basis of bill-color categorization alone, 88 individuals qualified provisionally as Nazca Boobies and 27 as Masked Boobies. Examples of individuals of each category, with scores of various colors and brightnesses, are shown in Figures 4-6.

\section{Bill Color Versus Age}

Provisional Masked Boobies varied little in scored bill color according to age. All three colors, dark blue, green, and yellow, appeared in similar frequency in the bases of the bills of birds in all categories of primary molt, from juveniles to definitive basic plumage. For the bill tip, both green and yellow appeared in all age groups, with a tendency for bill tips to be brighter, with more yellow and less green, in birds in definitive plumage. In provisional

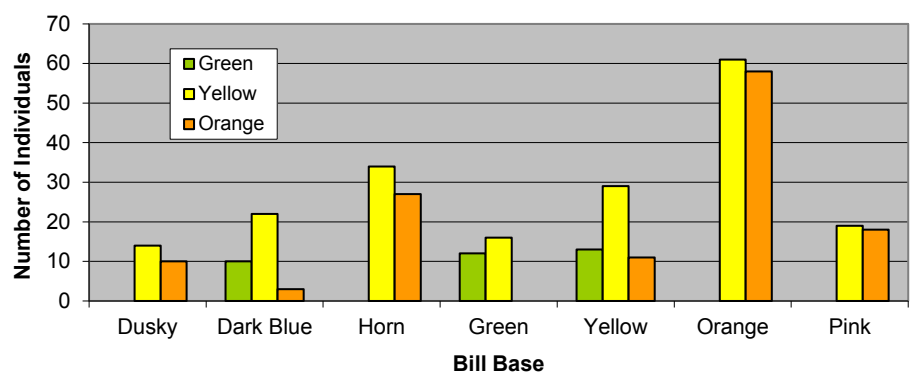

FIGURE 3. Distribution of bill-tip color according to bill-base color in Masked and Nazca boobies recorded in California. Note that no or few birds with blue, green, or yellow in the base also showed orange in the tip, whereas no birds with dusky, horn, orange, or pink in the base also showed green in the tip. 


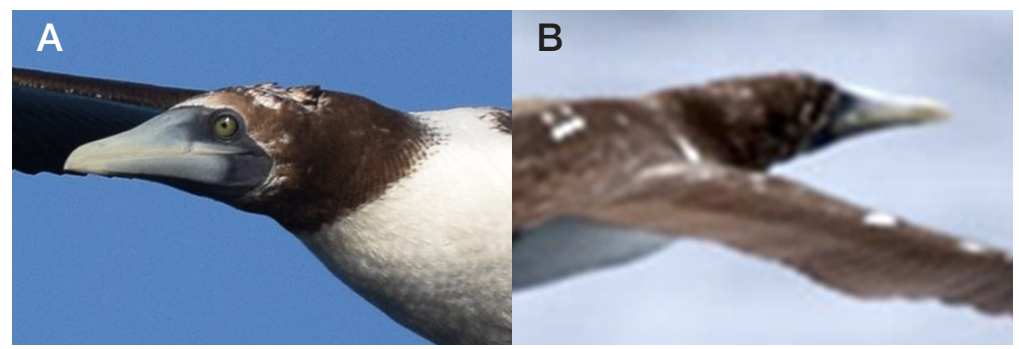

Figure 4. Bill color in a provisionally identified juvenile Masked Booby (A, off Point Fermin, Los Angeles County, 22 August 2018; CBRC 2018-106) and a provisionally identified juvenile Nazca Booby (B, off Pt. Loma, San Diego County, 23 July 2010; CBRC 2010-077). In neither of these birds had p1 of the juvenile plumage been replaced, so their estimated age is $<8$ months. Masked Boobies appear to acquire a bluish bill base and a greenish tone to the remainder of the bill, whereas Nazca Boobies appear to acquire horn coloration in the base and a yellow to orange-yellow or golden-yellow bill tip that is brighter at a younger age than is found in the Masked Booby. Although the photograph of the apparent Nazca Booby above (B) is rather soft, the golden-yellow tip is readily discernable. These birds were scored as (A) bill base medium-bright greenish blue and bill tip medium greenish yellow; and (B) bill base medium dull dusky-horn and bill tip medium orangish yellow. See also Figure 5 .

Photos by Naresh Satyan (A) and Michael H. Smith (B)

Nazca Boobies, the color of the bill base generally changed from dusky (occasionally tinged bluish) in juveniles, to horn during the first wave of primary molt, to orange and pink in birds in definitive plumage. The frequency of horn coloration in the bill base gradually dropped, from $65 \%$ in 23 birds through the first dropping of $\mathrm{p} 6$, to $43 \%$ of 7 birds in third basic plumage (that had completed the first molt of primaries), to $0 \%$ of 32 birds in definitive basic plumage. Horn was replaced by orange, which was found in $20 \%$ of 10 birds in which $\mathrm{p} 5$ had not yet been replaced for the first time, $44 \%$ of 23 birds with p5 to $\mathrm{p} 8$ molting, and $100 \%$ of 32 birds in definitive basic plumage. Seven birds showed both horn and orange in the bill base; in the four of these in which primary molt could be assessed it scored between $\mathrm{p} 6$ and p9. No pink appeared until definitive basic plumage was attained; it was scored in $56 \%$ of 32 birds in this plumage.

The tips of the bills of provisional Nazca Boobies were largely orangish or golden yellow. Some $82 \%$ of 61 birds through the second cycle of primary molt (including $65 \%$ of 17 birds that had not yet dropped p5) showed this color, while $28.1 \%$ of 32 birds in definitive plumage had gained more orange coloration to the tip and were scored with bills of yellowish orange (i.e., with orange rather than yellow predominating). It is possible that bill bases gain more pink and bill tips gain more orange before or during courtship or breeding, then become yellower (duller) during molt and nonbreeding periods, paralleling the changes in the soft-part colors of herons, rails, and other taxa (Pyle 2008). However, because the schedule of breeding of the individuals photographed is unknown, I could not address seasonal variation in bill color 


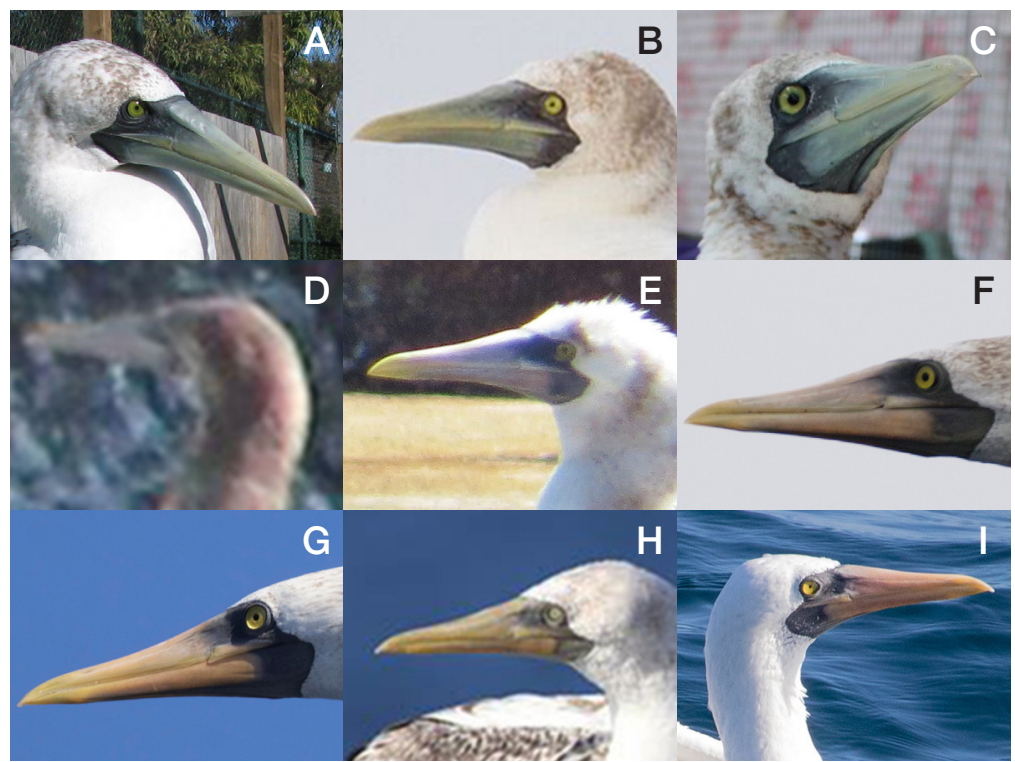

Figure 5. Progression of bill colors in provisionally identified Masked (A-C) and Nazca (D-I) boobies through their first primary molt. Note the bluish and greenish tones to the bills of the apparent Masked Boobies vs. the horn and orange tones to the bases and brighter golden-yellow tips to the bills of the apparent Nazca Boobies. The bill color of provisional Masked Boobies does not change substantially during the first plumage cycle (see also Figure 4). That of provisional Nazca Boobies gets brighter and oranger with age, but not necessarily consistently. Some younger birds (e.g., those in photos $\mathrm{E}$ and $\mathrm{G}$ ) can show bills brighter than those of birds older according to molt progression (e.g., F and H, respectively). See Table 1 for locations, dates, scores, and photo credits.

with this data set. Photographs supporting these bill color patterns in both species as provisionally identified are shown in Figures 4-6.

The brightness of the color of both the bill base and the bill tip also varied by both apparent species and estimated age. Among the 120 individual boobies I scored for bill color, I rated the bases of four bills as dull, of nine as medium-dull, of 24 as medium, of 52 as medium-bright, and of 31 as bright. With respect to the tips I rated one as dull, seven as medium-dull, 16 as medium, 56 as medium bright, and 40 as bright. The bill tips averaged brighter overall and brighter relative to the bill bases on provisional Nazca Boobies than on provisional Masked Boobies at the same stage of molt of the primaries (Figure 7). Among birds with primary scores of p1 to p8, 7\% of 14 Masked Boobies but $58 \%$ of 40 Nazca Boobies had the bill tip brighter than the base. By contrast, $43 \%$ of 14 Masked Boobies but only $2.5 \%$ of 40 Nazca Boobies had the tip duller than the base. Examples of individuals with various scores for bill brightness are shown in Figures 4-6. 
TABLE 1 Approximate Ages, Bill-Color Scores, and Background Data on Masked and Nazca Boobies Shown in Figure 5

\begin{tabular}{|c|c|c|c|c|c|c|c|}
\hline $\begin{array}{l}\text { Apparent } \\
\text { species }^{a} \\
\text { and photo }\end{array}$ & $\begin{array}{l}\text { CBRC } \\
\text { record }\end{array}$ & County & Date $^{b}$ & $\begin{array}{c}\text { Age } \\
\text { (months) }\end{array}$ & Bill base ${ }^{d}$ & Bill tip ${ }^{d}$ & Photographer \\
\hline \multicolumn{8}{|l|}{ Masked } \\
\hline A & $2007-215$ & Los Angeles & 6 Oct 2007 & 9 & MB-GB & MB-YG & Akiko Kannan \\
\hline B & 2011-217 & Orange & 17 Dec 2011 & 14 & MB-YB & MB-YY & $\begin{array}{l}\text { Christopher } \\
\text { Taylor }\end{array}$ \\
\hline C & 2018-160 & Ventura & 6 Oct 2018 & 16 & MB-BG & ME-YY & Trish Gussler \\
\hline \multicolumn{8}{|l|}{ Nazca } \\
\hline $\mathrm{D}^{e}$ & 2015-103 & Santa Barbara & 28 Sep 2015 & 8 & MD-HH & MB-OY & Jean Scholes \\
\hline $\mathrm{E}$ & 2018-100 & Los Angeles & 19 Aug 2018 & 11 & ME-HH & MB-OY & $\begin{array}{l}\text { Brittany } \\
\text { O'Connor }\end{array}$ \\
\hline F & 2018-159 & San Diego & 23 Sep 2018 & 13 & ME-OH & MB-OY & Nicole Desnoyers \\
\hline G & $2018-243$ & Ventura & 5 Oct 2018 & 13 & $\mathrm{MB}-\mathrm{OO}$ & $\mathrm{MB}-\mathrm{YO}$ & Michael Force \\
\hline $\mathrm{H}^{e}$ & 2013-287 & Los Angeles & 13 Oct 2013 & 14 & MB-HH & MB-OY & Jon Feenstra \\
\hline I & $2018-060$ & San Diego & 10 Jun 2018 & 15 & MB-OO & BR-OY & Mel Senac \\
\hline
\end{tabular}

${ }^{a}$ Apparent species is as identified in this analysis of bill color; identification in CBRC records may not match. ${ }^{b}$ Date is that of photograph; may differ from date of first observation listed in Appendix.

${ }^{c}$ Approximate age in months based on progression of primary molt (see text).

${ }^{d}$ Bills scored for brightness (first two characters) and color (second two characters). For brightness: MD, medium dull; ME, medium; MB, medium bright; BR, bright. For colors, the first letter represents the secondary color and the second letter represents the dominant color (e.g., GB indicates greenish blue or blue washed green): G, green; Y, yellow; B, dark blue; H, horn (medium-pale brownish, often tinged mustard or olive); $\mathrm{O}$, orange.

${ }^{e}$ Accepted as a Masked/Nazca booby by the CBRC.

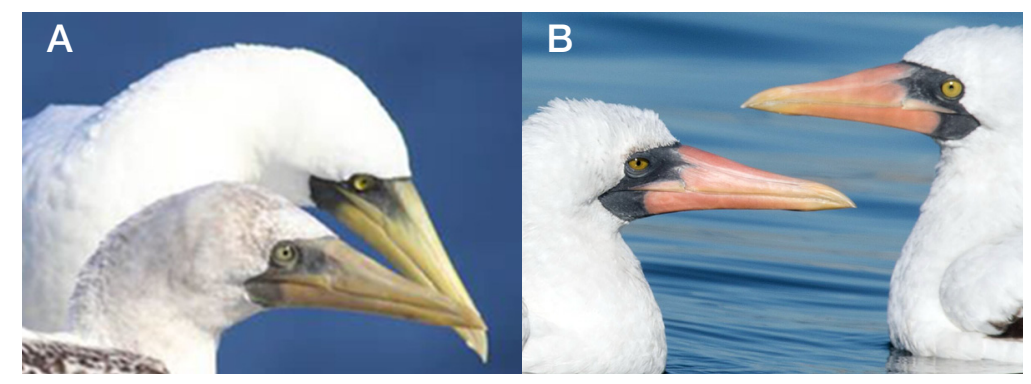

FIGURE 6. Bill color in adults (definitive plumage) of the Masked Booby (A, rear bird) and Nazca Boobies (B). The front bird in photo $\mathrm{A}$ is the same individual as in Figure $5 \mathrm{G}$ (which see for bill-color scoring), provisionally identified as a Nazca Booby. In definitive basic plumage these species differ diagnostically in bill color. A, rear bird, CBRC 2013-173, Los Angeles Co, 13 October 2013, bill base bright greenish yellow, bill tip bright yellow; B, 2017-155, San Diego Co., 13 December 2017, bill bases bright pinkish orange (left) and bright orange (right); bill tips bright yellowish orange in both birds. 


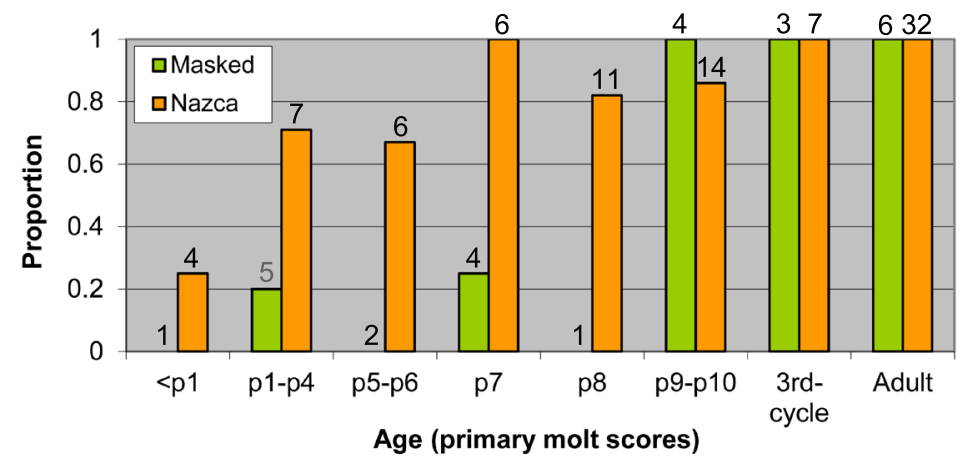

Figure 7. Proportion of provisionally identified Masked and Nazca boobies with medium-bright or bright bill tips by primary score and thus estimated age (see Figures 4-6 for examples of scores for colors of the tip and base of the bill). Sample sizes given above each bar. In birds in which the juvenile p9 has not yet been replaced, the proportion of bills whose tip is brighter than the base is greater in the Nazca than in the Masked Booby (see also text).

Thus younger presumed Nazca Boobies with dusky and horn bill bases $(n$ $=11$ in my sample; mean score for primary molt 4.3 ) transitioned to orangish horn $(n=7$; mean 4.7$)$ then orangish or pinkish-orange bases $(n=51$; mean 6.0), while often showing brighter orangish-yellow or golden bill tips, a pattern not appearing in provisional Masked Boobies at any age. Among provisional Masked Boobies, $82 \%$ of 17 birds in the first and second cycles (before completion of the first molt of primaries) showed green in either the bill base or bill tip, whereas none of 47 provisional Nazca Boobies of these ages showed green in the bill base or tip (Figures 4-6).

\section{Variation in Body Plumage and Wing Coverts by Age and Species}

Mean scores for body plumage and wing coverts, by progression of primary molt (age), are shown in Figure 8. I found little or no difference between the provisionally identified species regarding change in any of the six areas of plumage evaluated. The head averaged slightly whiter in Masked than in Nazca boobies once p7 had dropped (mean head score for categories from $\mathrm{p} 7$ to the second basic plumage was 4.67 in 12 Masked Boobies and 4.16 in 38 Nazca Boobies). Otherwise there appeared to be no species-specific patterns by age among plumage scores. Therefore, in Figure 8, all birds are pooled.

The colors of the nape and underwing of the Masked and Nazca boobies have been suggested as changing at different rates, at least on average (Roberson 1998, Pyle 2008, Howell et al. 2014, Howell and Zufelt 2019). In my sample, by the time $\mathrm{p} 7 \mathrm{had}$ dropped, the nape had become fully white in all boobies. Prior to this, the mean nape score was 3.5 in eight provisional Masked Boobies and 2.5 in 16 provisional Nazca Boobies. Thus there was a tendency for the nape to be whiter in young Masked than in young Nazca boobies (as first suggested by Roberson 1998), but there was variation and overlap, especially among Nazca Boobies. For example, among birds that 


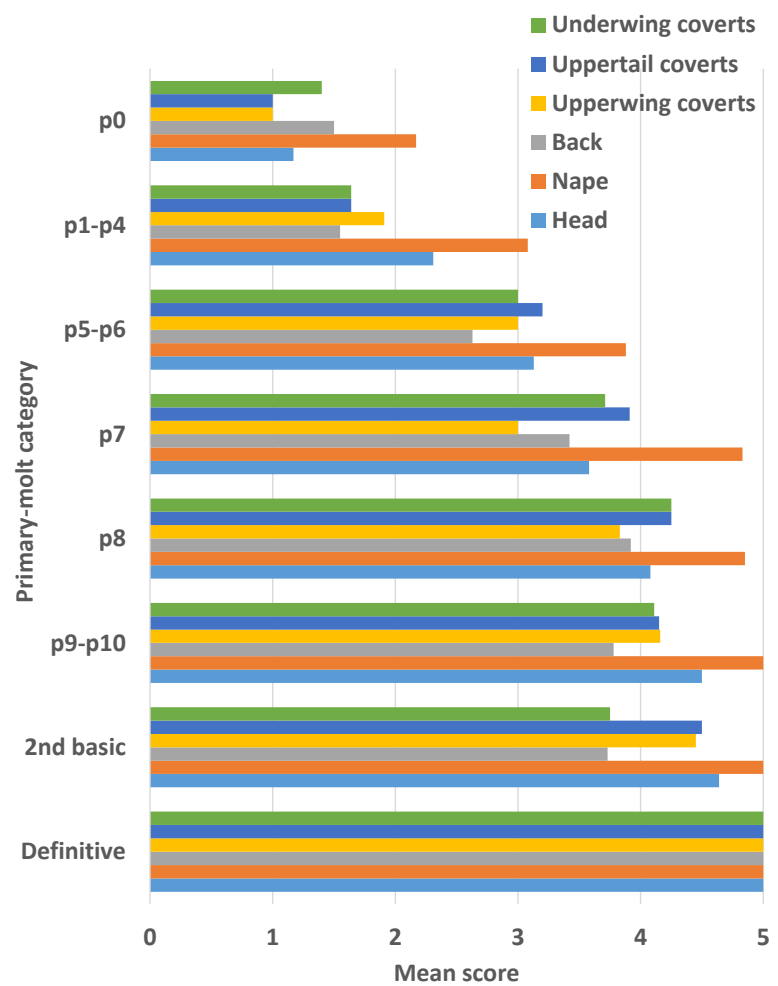

FIGURE 8. Development of appearance in six areas of body plumage and wing coverts with progression of molt of the primaries (age). A score of 0 indicates completely or almost completely dark, while a score of 5 indicates completely white. All individuals pooled, as few or no species-specific differences were evident (see text). Sample sizes: 5-6 (for category p0), 7-8 (p1-p4), 5-7 (p5-p6), 7-10 (p7), 7-12 (p8), 8-15 (p9-p10), 3-7 (second basic), and 15-25 (definitive basic). Sample sizes are presented as a range because not every bird in each age category could be scored for every variable.

had not yet dropped p7, apparent Nazca Boobies (by bill color) showed fully white napes (score 5) in at least three cases (CBRC 2018-100, 2018-159, and 2018-243), while one Masked Booby (CBRC 2014-099) showed a darker nape (score 3 ). It is possible that most birds had begun molting their nape feathers by the time they reached California, and that differences may be more marked among younger juveniles closer to the breeding grounds. Among the juveniles in my sample ( $\mathrm{p} 1$ not yet replaced), one apparent Masked Booby (CBRC 2018-106) had a fully white nape (score 5), while four Nazca Boobies had nape scores of $1,2,2$, and 2, supporting this species-specific difference.

Underwing-covert scores showed no consistent patterns by species. Mean scores for each provisionally identified species were the same or very similar for all age categories through the second and third basic plumages (sometimes 
greater in provisional Masked Boobies, sometimes greater in provisional Nazca Boobies). For birds undergoing the first wave of primary molt, the mean underwing score was 2.4 in five Masked Boobies and 2.9 in 26 Nazca Boobies, opposite to the pattern reported by Howell and Zufelt (2009), darker in the Nazca than in the Masked.

In birds in second or third basic plumage in which p9 and/or p10 were growing or had completed growth, the nape and uppertail coverts had become fully white, whereas mean scores for the back of $3.8(n=29)$ and underwing coverts of $4.0(n=13)$ indicated the birds retained more dark feathering in these areas. However, at least three birds meeting these criteria scored 5 (pure white) for either the back or the underwing coverts, and several others (e.g., those in CBRC 2018-098, 2018-101, and 2018-108) had definitive plumage except for very slight mottling in these areas and/or the upperwing coverts. This suggests that some birds may approach the definitive color pattern by the time the last juvenile primary is dropped. Note that the difference in Figure 8 between second basic plumage and definitive basic appearance is based on circular reasoning (all tracts being white categorizing definitive basic appearance), so it is quite possible that some of the sample of birds of definitive appearance includes some in second or early third basic plumage. Among birds in which the second basic outer primary was fully grown there appeared to be no differences in any plumage score relative to progression of the second molt of inner primaries, although the sample size for this category was small $(n=6)$.

\section{Variation in the Central Rectrices by Age and Species}

Boobies provisionally identified as the Nazca by bill color consistently showed more white in the central pair of rectrices, of all three feather generations-juvenile, second basic, and definitive basic-than did those provisionally identified as the Masked (Figure 9). The central rectrices of most provisional Masked Boobies, of all three feather generations, scored 1 or 2; only two of 21 birds received a score of 3 (cf, Figure 10; CBRC records

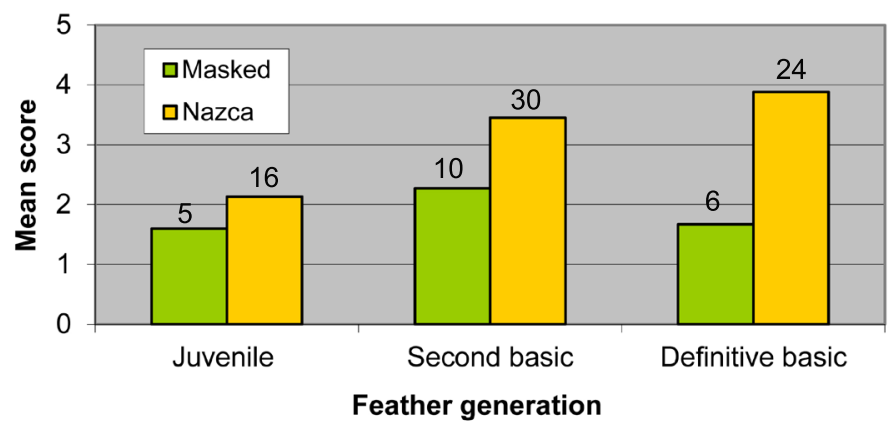

FIGURE 9. Mean score for extent of white in three generations of central rectrices of presumed Masked and Nazca boobies. Sample sizes are given above bars. Scores vary from 1 (central rectrix completely dark beyond uppertail coverts) to 5 (central rectrix completely or almost completely white); see Figure 10 for examples. 
2007-215 and 2018-160), and one received a score of 5 (2006-155). In the last individual, one or both central rectrices appeared to be pure white, without markings, and thus may have been leucistic (most central rectrices that were scored as 5 had reduced dark markings at the tip). In all three of these cases (score $>2$ ) the rectrices were second basic. Among provisional Nazca Boobies, six of 70 birds, all with juvenile rectrices (e.g., 2018-243; cf. Figure 10), received a score of 1 . Notably, these included a bird confirmed by DNA analysis as a Nazca Booby (2001-107, which reached California on a ship; see photo in CBRC 2007:277). In all nine of these birds, the bill color clearly supported the provisional species identification. The extent of white in the rectrices also increased with age in the Nazca Booby (Figure 9), with the proportion of birds with central-rectrix scores of 4 or 5 increasing from $12 \%$ of 17 birds with juvenile rectrices to $50.0 \%$ of 30 birds with second basic rectrices to $55.2 \%$ of 29 birds with definitive basic rectrices. Photographs of tails exemplifying the scores, including some interesting variations, are shown in Figure 10.

\section{DISCUSSION}

\section{Molt, Plumage, and Age}

Molt and age. The majority of Masked and Nazca boobies reaching California were undergoing molt of primaries: $82.4 \%$ of 108 birds whose stage of molt status was visible in photographs. Of actively molting birds, $68.7 \%$ of 83 were undergoing the first molt of primaries. A large number of these (70\% of 66 with known primary-molt score) were observed when the juvenile p6 to p10 were being replaced (Figure 2), and in no birds did the molt of juvenile primaries appear to be suspended. Post-juvenile dispersal thus appears to account for most records of these two species in California, and the predominance of birds in molt suggests that second- and third-cycle boobies, lacking the constraints of breeding, may replace their flight feathers continuously while foraging at sea (Pyle 2008, Howell 2010). Among adults, $57 \%$ of 30 birds whose status with respect to molt could be identified were actively molting, suggesting that these boobies may reach California shortly after post-breeding dispersal (before molt begins) but also later, once definitive prebasic molt commences. The predominance of first-cycle, second-cycle, and third-cycle birds in this sample provides an opportunity for plumage change to be examined in relation to replacement of primaries.

Dorward's (1962) analyses of banded Masked Boobies of known age on Ascension Island in the Atlantic Ocean allow estimation of the age of birds replacing their primaries for the first or second time. In Dorward's sample, p1 was dropped when the birds were about 7 months of age (about two months post-fledging; Nelson 2005), each successive juvenile primary from 1 to p7 was dropped about a month later than the preceding one, and the longer primaries from $\mathrm{p} 8$ to $\mathrm{p} 10$ were each dropped about 2 months following the preceding primary. Thus a bird growing p1 during the second prebasic molt should be 8 months old, one growing p6 should be 13 months old, one growing p8 should be 16 months old, and one growing p10 should 20 months old (Figure 2), as long as molt is continuous. On the basis of Dorward's analysis 


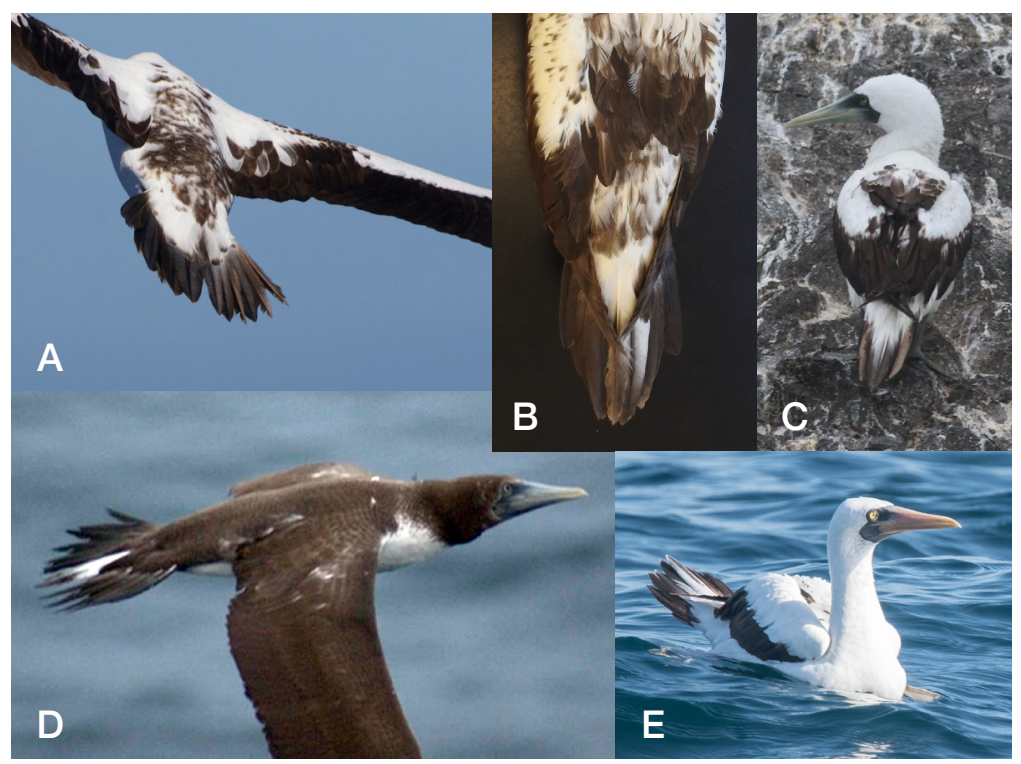

FIGURE 10. Examples of central-rectrix scores (1-5) in provisionally identified Masked and Nazca boobies. A, Ventura County, 5 October 2018 (CBRC 2018-243). One of six apparent Nazca Boobies assigned a central rectrix score of 1 (all dark beyond coverts). In this case the rectrices represent the second basic plumage. B, Nazca Booby, Ventura County, died 7 August 2018 (CBRC 2018-088, LACM 121174). Left rectrix juvenile with a score of 2; right rectrix second basic with score of 3, exemplifying an increase in white in the central rectrix in successive generations of feathers (see Figure 9). C, Ventura County, 27 September 2018 (CBRC 2018-160). Provisionally identified Masked Booby assigned a central-rectrix score of 3 . In this case both rectrices represent the second basic plumage. D, Los Angeles County; 1 November 2007 (CBRC 2008-070) Different photographs of this bird show conflicting bill colors, so I did not identify it to species by bill color alone; however, the extent of white in the juvenile central rectrices (score 4) led to a provisional identification as a Nazca Booby. E, San Diego County, 10 June 2018 (CBRC 2018-060), Nazca Booby with central rectrices, of the definitive plumage, scored 5.

Photos by (A) Michael Force, (B) Kimball Garrett, (C) David Vander Pluym, (D) Michael Smith, and (E) Nancy Christensen

of birds that had completed the second prebasic molt, I estimate that those in my sample in which the second wave had reached p3, p4, and p5 were about 21,22 , and 23 months of age, respectively. These estimates must be considered approximate because of uncertainty in the precise age of chicks when Dorward banded them and individual variation in the rates of primary growth. By the time p6 was dropped, these rates could differ by up to a month. Only six boobies in my sample had not begun the first primary molt, suggesting that only a small proportion of the boobies reaching California are $<2$ months post fledging ( $<7$ months of age). Most are first observed when p6-p10 are growing (Figure 2), when 6-17 months post fledging (11-22 months of age). 
Plumage and age. This analysis implies that some Masked and Nazca boobies assume definitive appearance by completion of the first wave of primary molt, at $\sim 22$ months of age. Most references on plumage maturation in the Masked Booby indicate that all third-cycle birds (in which the second wave of primary molt has begun) should have dark mottling in at least the lower back and wing coverts (Witherby et al. 1940, Marchant and Higgins 1990, Nelson 2005, Pyle 2008, Grace and Anderson 2009, Howell and Zufelt 2019), the last areas of the plumage to attain definitive appearance, as I also found (Figure 8). Some references (e.g., Pyle 2008, Grace and Anderson 2009, Howell and Zufelt 2019) indicate that some individuals in their fourth cycles may retain black mottling in these areas. But in this analysis I found that no birds in which the second and third waves of replacement of primaries overlapped (in a Staffelmauser pattern) retained black mottling in the plumage. Therefore essentially all of these boobies achieve definitive appearance during the third prebasic molt, by about 32 months of age according to Nelson (2005), but my analysis suggests that some birds may reach definitive appearance by an age of 20 months.

I recommend that the age of these boobies should thus be estimated solely from the progress of primary molt. Birds wearing their second generation of primaries and white body plumage but retaining light mottling on the lower back, upperwing coverts, and underwing coverts are in their third plumage cycle as defined here (20-32 months of age, depending on progress of the second wave of primary replacement). These criteria apparently apply to the Masked and Nazca Boobies equally (cf. Figure 8 ). The Northern Gannet (Morus bassanus) has been confirmed not to reach definitive appearance until at least the fourth plumage cycle at $36+$ months of age (Cramp and Simmons 1977, Nelson 2005, Pyle 2008, Howell and Zufelt 2019). Perhaps the tropical foraging environment allows for more frequent feather replacement on an annual basis and a quicker rate of plumage change in Masked Booby than is possible in the less productive, colder northern waters the Northern Gannet most commonly inhabits in winter.

\section{Identification of the Masked and Nazca Boobies in Predefinitive Plumage}

I propose that, given good photographs of bill coloration, the majority of Masked and Nazca boobies can be identified to species away from their nesting colonies. Masked Boobies have bluish-green bill bases with greenishyellow tips, and these colors appear to be relatively consistent while becoming brighter with age, from juvenile to definitive plumage. Nazca Boobies, by contrast, from juveniles through the first wave of primary molt, have duskier bill bases that are mixed with horn color (medium-pale brownish, often tinged mustard or olive) at younger ages and bill tips that are a brighter yellow and usually tinged orangish or golden. No Nazca Boobies show green in the bill and only a small proportion show bluish in the base (see below). In addition, the golden-yellow tips of Nazca Booby bills are often $(>55 \%)$ brighter than the bases, an effect observed in only a small proportion $(<8 \%)$ of Masked Boobies in predefinitive plumage. During the second basic and in later plumages, the base of a Nazca Booby's bill becomes bright orange to pinkish orange and the tip becomes bright orangish yellow to yellowish orange (Pitman and Jehl 1998, 
Roberson 1998, CBRC 2007, Pyle 2008, Howell and Zufelt 2019). Younger Nazca Boobies thus have horn-colored bill bases (mixed dusky or occasionally bluish) that become mixed horn and orange, then orangish or pinkish orange, with brighter orangish-yellow or golden bill tips, a combination of colors not shown by Masked Boobies at any age (Figures 4-6). Even from poor photographs (e.g., in Figures 4 and 5), I propose that a brighter, goldentipped bill is enough to confirm a Nazca Booby (Figure 4B). Rottenborn et al. (2016) suggested that the bill of the Nazca Booby averages thinner and with a culmen more concave than in the Masked Booby. Although I did not evaluate possible differences in bill shape, the photos in Figures 4-6 seem to support this hypothesis. Because subtle differences in bill shape cannot be quantified easily in photos taken in the field at various angles, this hypothesis should be tested with measurements of specimens.

Photographs at www.eBird.org and other websites indicate that these color differences may become evident in juveniles at or near breeding colonies. For example, see photographs of juvenile Masked Boobies from Clipperton Atoll (www.oceanlight.com/photo/brown-booby-clippertonisland-33088.jpg) and in the Northwestern Hawaiian Islands (www.ebird. org/checklist/S54437701, www.storage.needpix.com/rsynced_images/ masked-booby-79774_1280.jpg), and of juvenile Nazca Boobies from the Galapagos Islands (www.ebird.org/checklist/S20648069, www.ebird.org/ checklist/S52286384, www.ebird.org/checklist/S57729904). More study on the breeding grounds, however, will be needed to clarify when exactly bill colors of nestlings ( $<5$ months old) at these colonies change from blackish to colors that may allow the two species to be distinguished, and the degree of individual variation in rates of bill-color change with age. Further investigation will also be useful in determining if the pattern of bill-color change I describe applies throughout the pantropical range of the Masked Booby. In some populations the bill of adults appears to average brighter than it does in the eastern Pacific Ocean.

More extensive white in the visible portions of the central pair of rectrices appears to be useful as a supporting character distinguishing the Nazca from the Masked Booby in some cases. As has been reported in the literature (Roberson 1998, CBRC 2007, Pyle 2008); however, each species' rectrices vary from completely dark to completely white (Figure 10). For example, one booby in my sample confirmed to be a Nazca Booby by DNA analysis (CBRC 2001-107) had all-dark central rectrices beyond the coverts (score 1), as do two juvenile Nazca Boobies with photographs in Howell and Zufelt (2019:307). Despite this overlap, I consider the lack of brown extending past the uppertail coverts (central rectrix score 1 here) a supporting character for the identification of Masked Boobies, especially those with second basic or definitive rectrices, whereas white extending well past the coverts (rectrix scores 3-5) can be considered a supporting character for the identification of Nazca Boobies, especially those with juvenile rectrices. Coloration of the nape and underwing coverts does not appear to be as helpful for distinguishing these two species, at least by the time they reach California. A white nape or hind collar in juvenile Masked Boobies vs. a dark nape in juvenile Nazca Boobies could be a supporting character on the breeding grounds, although 
Roberson (1998) reported the opposite pattern in as many as $25 \%$ of the photographs of juveniles of each species that he examined.

Masked or Nazca boobies whose bills have not been well photographed or described should not be identified to species, except in cases of confirmation by DNA analysis (cf. CBRC 2001-107 and 2013-285; CBRC 2007, Rottenborn et al. 2016). Occasionally, photographs of the same booby show conflicting bill colors (e.g., Figure 11). A problem with a few records prior to 2010 may be related to use of older photographic formats (e.g., Kodak Kodachrome vs. Ektachrome slides) and the effect of lighting or production on these formats (Figure 11A-D). It appears that advancement of digital imaging technology since 2010 has lessened this problem, as the apparent bill color did not vary as much among more recent photographs taken with different cameras and in various lighting situations. Another problem is variation in the warmth of the color as seen in the same photograph on different computer monitors (Singer et al. 2020), which has caused CBRC members to vote differently on records of the same bird. Perhaps this problem will also lessen with technological advances in computer monitors. I predict, however, that a greater understanding of bill color variation, as I have documented, will improve the accuracy of identifications as observers account for potential variations in photographs taken under different lighting and in computer monitor display.

Three birds (CBRC records 2015-103, 2018-138, and 2018-244) were scored with blue in the bill base but medium-bright orange-yellow in the bill tip. Both 2015-103 (Figure 5D) and 2018-144 had medium bluish-horn bill bases, and this, as well as their brighter golden bill tips (and score of 3 for the second-basic rectrices of 2018-144) lead me to identify them provisionally as Nazca Boobies. Record 2018-138 was unique in its bill having a medium-bright bluish base (without horn) and orange-yellow tip of the same brightness, defying categorization by the criteria I have outlined (Figure 11E, F). Although I suspect it was a Nazca Booby by bill color, it may have been a hybrid. Otherwise, birds with intermediate characters or possible hybrids accounted for a very small proportion of my sample (4.2\% of 120$)$.

\section{The Recent Invasion of California by the Masked and Nazca Boobies}

According to my sample of provisional identifications, Nazca Boobies far outnumber Masked Boobies in California (92 vs. 27 individuals through 2019). Only 32 of the provisional Nazca Boobies in my sample were identified prior to 2018 (vs. 60 in 2018 or 2019), whereas the 26 records of the Masked Booby are more evenly distributed between these two periods (12 before 2018 and 14 in 2018 or 2019). Pitman and Jehl (1998) and Roberson (1998) reported the Nazca Booby's pelagic distribution as more coastal than that of the Masked, possibly leading to observations of the Nazca being more frequent near the California coast. The recent increases of both species as well as other boobies in California may also be affected by global ocean warming as connected to El Niño-Southern Oscillation and climate change (Anderson 1989, Tompkins et al. 2017, Cha et al. 2018). Potentially, temperature differentials in the eastern Pacific are diminishing as the ocean warms, leading to a greater likelihood of Nazca Boobies dispersing into waters of the California Current, but further research is needed on this. Such factors may also lead 


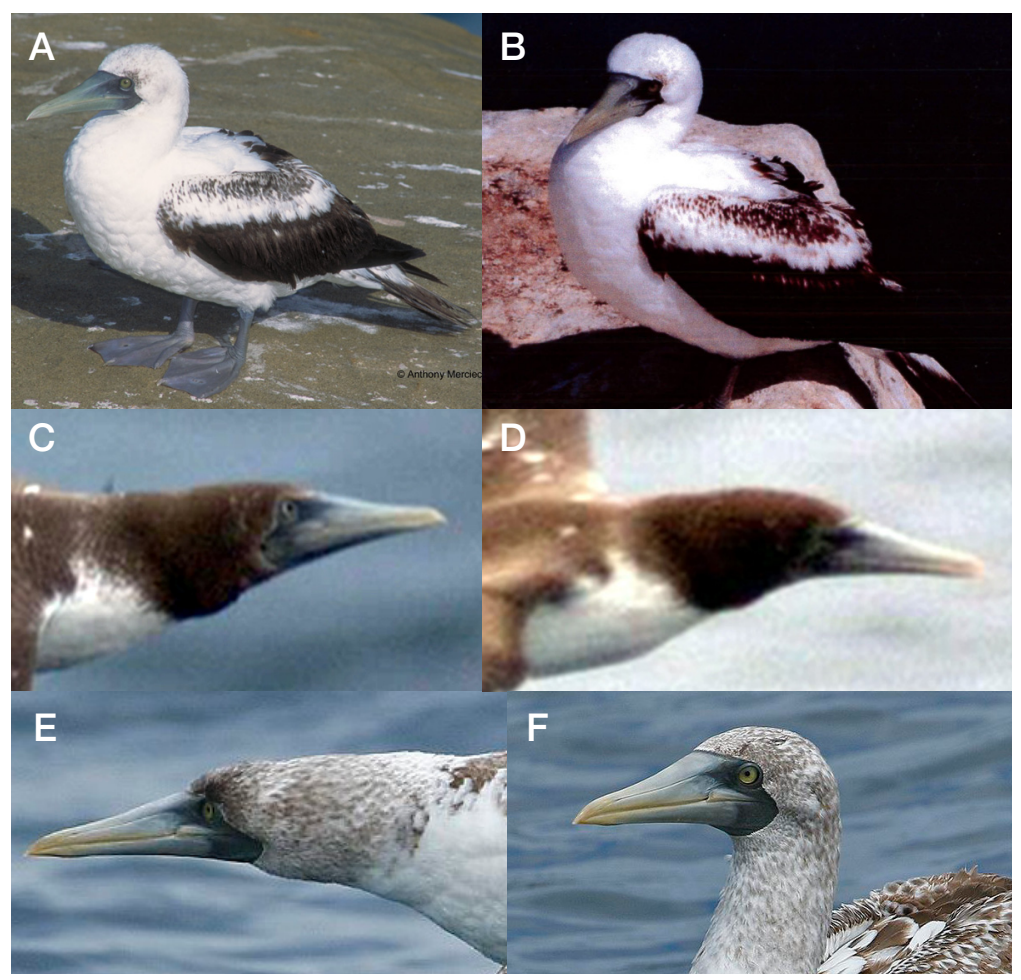

FIGURE 11. Boobies with bill-coloration scores showing conflicting colors relative to species identification. A, San Diego County, 30 December 2001 (CBRC 2002-001) and B, Orange County, 11 February 2002 (CBRC 2002-038) represent the same individual, as details of the plumage match. From photograph A, I scored the bill base as medium (in brightness) dark blue and the tip as medium-bright greenish yellow, suggesting a Masked Booby. From photograph B, I scored the bill base as medium-dull dusky horn and the tip as medium orangish yellow, suggesting a Nazca Booby. C and D, Los Angeles County, 1 November 2007 (CBRC 2008-070), one bird photographed at the same time but in different lighting. From photograph C, I scored the bill base as medium (in brightness) dark blue and the tip as medium yellow, suggesting a Masked Booby. From photograph D, I scored the bill base as medium dusky horn and the tip as medium-bright orangish yellow, suggesting a Nazca Booby. On the basis of photographs $\mathrm{B}$ and $\mathrm{D}$, the precise color of the bill tips in photographs $\mathrm{A}$ and $\mathrm{C}$, examination of additional photographs, and, for $\mathrm{C}$ and $\mathrm{D}$, a central rectrix score of 4, as shown in Figure 10, I suspect both are Nazca Boobies. This problem of bill-color variation in photographs appears to have lessened with technological advancements in digital imagery after about 2010. E and F, photographed southwest of San Clemente Island, Los Angeles County, on 6 September 2018 (CBRC 2018-138), I scored as having a medium-bright bluish bill base and a medium-bright orange-yellow bill tip, contradictory characters precluding categorization to species (see text).

Photos by (A) Anthony Mercieca, (B) Don Lockshaw, (C and D), Michael H. Smith, and ( $E$ and $F)$ Dave Pereksta 


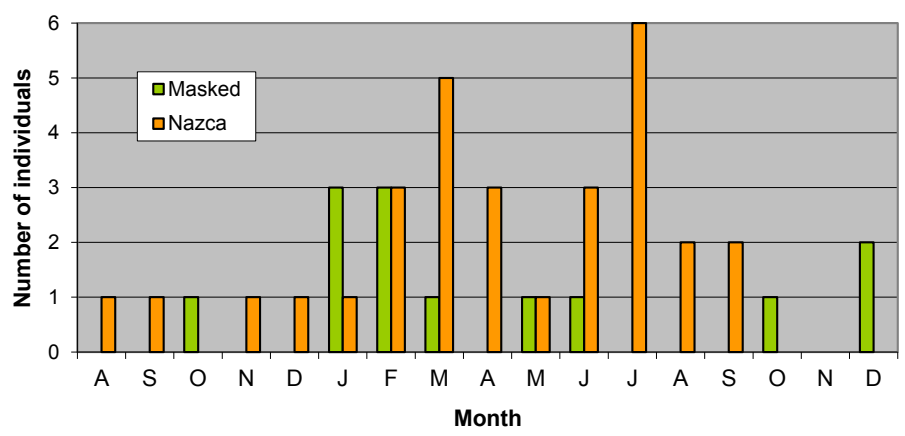

FIGURE 12. Estimated months in which provisionally identified Masked and Nazca boobies were hatched, from August 2016 to December 2017, as based on estimated age in months (see text) and date of observation. Note the preponderance of apparent Nazca Boobies estimated as hatching from February to September 2017, indicating that this breeding period may have been relatively productive for this species, which in turn may have been a factor fueling the 2018-2019 surge in records to California. By contrast, hatchings appear to have been less seasonal in apparent Masked Boobies that reached California in 2018 and 2019.

to a paucity of food resources in the area, resulting in greater dispersal of boobies (cf. Tompkins et al. 2017), as far as California. Another factor that may contribute to invasions or die-offs of seabirds is a spike in productivity. From the estimated months of hatching among Nazca Boobies reaching California in 2018 and 2019 (Figure 12), it would appear that a productive breeding season from February to September 2017 may have been a factor in this species' invasion of California, despite a warning that its breeding success may be declining (Tompkins et al. 2017). All of these factors may be contributing to the increase in boobies recorded over the past decade in California.

\section{Standardization and Possible Re-evaluation of CBRC records}

As part of this analysis I reviewed every CBRC record of the Masked and/ or Nazca boobies supported by photographs. One of my goals was to apply standard criteria for identification by bill color, summarized above, when possible. Provisional identifications as based on my initial bill-color analyses differed from the CBRC's decision on 37 of the 134 individual birds. In some of these cases, however, photographs only marginally depicted the bird's bill color, and my scores may not have been accurate. In others the identifications suggested by the pattern of the central rectrices and the bill color conflict. With these eliminated, approximately 25 records remain that I believe the CBRC should re-evaluate. Most of these records were accepted as representing the Masked Booby but I believe should be left unidentified, or had been left unidentified but I think represent the Nazca Booby.

\section{ACKNOWLEDGMENTS}

Foremost I acknowledge the CBRC's process, those who submitted written documentation and photographs to the CBRC, and past and current CBRC members for 
evaluating and commenting upon these records. CBRC members that voted on most or all records in 2018 and 2019 were Jon Dunn, Jon Feenstra, Rob Fowler, Lauren Harter, Guy McCaskie, Kristie Nelson, Jim Pike, Adam Rinkert, Steve Rottenborn, Adam Searcy, Dan Singer, Justyn Stahl, Susan Steele, and Scott Terrill. I especially thank CBRC Secretary Tom Benson for feedback on records, making available impending records, and reviewing a draft of the manuscript. I also thank Linnea Hall and Adam Searcy of the Western Foundation of Vertebrate Zoology for scanning past records and Don Roberson for help with literature. Jon Dunn, Robert L. Pitman, and Steve N. G. Howell provided critical reviews that helped "reel me in" and led to an improved manuscript. This is contribution 648 of The Institute for Bird Populations.

\section{LITERATURE CITED}

American Ornithologists' Union (AOU). 2000. Forty-second supplement to the American Ornithologists' Union Check-list of North American Birds. Auk 117:847-858; doi.org/10.1093/auk/117.3.847.

Anderson, D. J. 1989. Differential responses of boobies and other seabirds in the Galapagos to the 1986-87 El Niño-Southern Oscillation event. Mar. Ecol. Prog. Ser. 52: 209-216; doi.org/10.3354/meps052209.

California Bird Records Committee (CBRC; R. A. Hamilton, M. A. Patten, and R. A. Erickson, eds.). 2007. Rare Birds of California. W. Field Ornithol., Camarillo, CA.

Cha, S-C., Moon, J.-H. , and Song, Y. T. 2018. A recent shift toward an El Niño-like ocean state in the tropical Pacific and the resumption of ocean warming. Geophys. Res. Lett. 45:11,885-11,894; doi.org/10.1029/2018GL080651.

Cramp, S., and Simmons, K. E. L. (eds.). 1977. The Birds of the Western Palearctic, vol. I. Oxford Univ. Press, Oxford, England.

Dorward, D. F. 1962. Comparative biology of the White Booby and the Brown Booby Sula spp. at Ascension Island. Ibis 103b:174-220; doi.org/10.1111/j.1474919X.1962.tb07244.x.

Everett, W. T., and Pitman, R. L. 1995. Avian specimens from Rocas Alijos, in Rocas Alijos (R. W. Schmieder, ed.), pp. 359-362. Kluwer Acad. Publ., Dordrecht, Netherlands.

Gibson, D. D., DeCicco, L. H., Gill, R. E. Jr., Heinl, S. C., Lang, A. J., Tobish, T. G. Jr., and Withrow, J. J. 2018. Fourth report of the Alaska Checklist Committee, 2013-2017. W. Birds 49:174-191; doi.org/10.21199/WB49.3.1.

Grace, J., and Anderson, D. J. 2009. Masked Booby (Sula dactylatra), in The Birds of North America (A. F. Poole, ed.), no. 73, version 2.0. Cornell Lab. Ornithol., Ithaca, NY; doi.org/10.2173/bna.73.

Howell, S. N. G. 2010. Peterson Reference Guide to Molt in North American Birds. Houghton Mifflin Harcourt, Boston.

Howell, S. N. G., and Pyle, P. 1997. Twentieth report of the California Bird Records Committee: 1994 records. W. Birds 28:117-141.

Howell, S. N. G., and Zufelt, K. 2019. Oceanic Birds of the World: A Photographic Guide. Princeton Univ. Press, Princeton, NJ; doi.org/10.2307/j.ctvg254dg.

Howell, S. N. G., Lewington, I., and Russell, W. 2014. Rare Birds of North America. Princeton Univ. Press, Princeton, NJ; doi.org/10.1515/9781400848072.

Marchant, S., and Higgins, P. J. (eds.). 1990. Handbook of Australian, New Zealand, and Antarctic Birds, vol. 1. Oxford Univ, Press, Oxford, England.

McCaskie, G., Rottenborn, S. C., Terrill, S. B., and Benson, T. A. 2018. The 42nd annual report of the California Bird Records Committee: 2016 records. W. Birds 49:238-257; doi.org/10.21199/WB49.4.1.

Nelson, J. B. 2005. Pelicans, Cormorants, and Their Relatives: The Pelecaniformes. Oxford Univ. Press, Oxford, England. 
Oregon Bird Records Committee (OBRC). 2020. The records of the Oregon Bird Records Committee: March 2020; https://oregonbirding.org/wp-content/ uploads/2020/03/recordsMarch2020.pdf.

Pitman, R. L., and Jehl, J. R. Jr. 1998. Geographic variation and reassessment of species limits in the "Masked" Boobies of the eastern Pacific Ocean. Wilson Bull.110:155-170.

Pyle, P. 2006. Staffelmauser and other adaptive wing-molt strategies in larger birds. W. Birds 37:179-185.

Pyle, P. 2008. Identification Guide to North American Birds, part 2. Slate Creek Press, Point Reyes Station, CA.

Roberson, D. 1998. Sulids unmasked: Which large booby reaches California? Natl. Audubon Soc. Field Notes 52:276-297.

Rottenborn, S. C., McCaskie, G., Daniels, B. E., and Garrett, J. 2016. The 39th annual report of the California Bird Records Committee: 2013 records. W. Birds 47:2-26.

Singer, D. S., Benson, T. A., McCaskie, G., and Stahl, J. 2020. The 43rd annual report of the California Bird Records Committee: 2017 records. W. Birds 51:2-26; doi.org/10.21199/WB51.2.1.

Tompkins, E. M., Townsend, H. M., and Anderson, D. J. 2017. Decadal-scale variation in diet forecasts persistently poor breeding under ocean warming in a tropical seabird. PLoS One 12(8): e0182545; doi.org/10.1371/journal.pone.0182545.

Vanderwerf, E., Becker, B. L., Eijzenga, J., and Eijzenga, H. 2008. Nazca Booby Sula granti and Brewster's Brown Booby Sula leucogaster brewsteri in the Hawaiian Islands and Johnston and Palmyra atolls. Mar. Ornithol. 36:67-71.

Witherby, H. F., Jourdain, F. C. R., Ticehurst, N. F., and Tucker, B. W. 1940. The Handbook of British Birds, vol. 4. H. F. Witherby, London.

Accepted 12 March 2020 